\title{
A prognostic model for the prediction of survival in cystic fibrosis
}

Karen M Hayllar, Simon G J Williams, Amelia E Wise, Shideh Pouria, Martin Lombard, Margaret E Hodson, David Westaby

\begin{abstract}
Background - The treatment for endstage cystic fibrosis is, where appropriate, double-lung, heart-lung or, occasionally, heart-lung-liver transplantation. Optimising the timing of transplantation depends upon an accurate prediction of survival, but while current criteria give some guidance to this, they are not based upon statistically derived prognostic models.

Methods - Data collected prospectively on 403 patients with cystic fibrosis, recruited between 1969 and 1987 (cohort A), were analysed by log rank and univariate Cox regression analysis to determine variables that accurately predict survival. The significant variables were then subject to time dependent multivariate Cox regression analysis to generate a prognostic model. The model was validated, within the study population, using split sample testing, and was subsequently validated in a further cohort of patients recruited since October 1988 (cohort B).
\end{abstract}

Results - One hundred and eighty eight $\mathbf{( 5 0 . 4 \% )}$ of the study cohort died within the study period. Percentage predicted forced expiratory volume in one second $\left(\mathrm{FEV}_{1}\right)$, percentage predicted forced vital capacity (FVC), short stature, high white cell count (WBC), and chronic liver disease (as evidenced by the presence of hepatomegaly) were negatively correlated with survival. These variables, when combined into a prognostic index, accurately predicted one year survival in the study population and in the cohort recruited since 1988 .

Conclusion - This prognostic index may prove valuable in predicting prognosis in other cohorts with cystic fibrosis and thereby improve the timing of transplantation.

(Thorax 1997;52:313-317)

Keywords: cystic fibrosis, prognostic model.

Cystic fibrosis is one of the commonest homozygous lethal genetic diseases among Caucasians with an estimated prevalence of one per 2000 births. ${ }^{1}$ Survival of patients with cystic fibrosis has improved considerably in recent years, predominantly as a result of improved respiratory care. ${ }^{23}$ Death, however, continues to be due, in most cases, to respiratory failure associated with cor pulmonale and pulmonary hypertension. ${ }^{3}$

Transplantation (double-lung, heart-lung or, occasionally, heart-lung-liver) remains the cornerstone of treatment in the terminal phase of the disease. ${ }^{4}$ Results have been encouraging in both adults ${ }^{5}$ and children ${ }^{6}$ and include enhanced survival and improvement in lung function.

To optimise the timing and results of transplantation, particularly in the presence of a donor shortage, there is a need for an accurate prediction of patient survival. Current recommendations for transplantation include those patients whose quality of life is severely impaired and whose life expectancy is less than two years. ${ }^{7}$ Current criteria suggested for recommending transplantation include percentage predicted forced expiratory volume in one second $\left(\mathrm{FEV}_{1}\right)<30 \%$ and significant carbon dioxide retention. ${ }^{8}$

The aim of the present study was to document predictors of short and medium term survival in cystic fibrosis, using time dependent Cox regression analysis, in order to create a prognostic model which allows accurate prediction of survival.

\section{Methods}

STUDY POPULATION

Cohort $A$

Cohort A consisted of all 403 patients with cystic fibrosis seen at the Royal Brompton Hospital, London between 1969 and 1987 and followed up until death or 1989. The Royal Brompton Hospital is a tertiary referral centre and, as a consequence, many patients have advanced disease. The hospital also cares for a large number of patients for whom it is their local cystic fibrosis centre and this cohort may have less severe disease, giving a heterogeneous population overall.

The diagnosis of cystic fibrosis was based on symptoms of malabsorption and pulmonary infection and was confirmed with an abnormal sweat sodium test $(>70 \mathrm{mmol} / \mathrm{l}) .^{3}$ All patients underwent an initial inpatient assessment upon referral to the hospital (table 1; pancreatic replacement being those taking pancreatic en- 
Table 1 Baseline variables at entry for patients from cohort $A$ included in the final time dependent analysis, together with the results of the initial statistical screening

\begin{tabular}{|c|c|c|c|c|}
\hline & $\begin{array}{l}\text { Median } \\
(n)\end{array}$ & $\begin{array}{l}10-90 \% \\
\text { range }\end{array}$ & $\begin{array}{l}\text { p value (log } \\
\text { rank analysis) }\end{array}$ & $\begin{array}{l}\text { p value (univariate } \\
\text { Cox regression) }\end{array}$ \\
\hline Age (years) & $20.17(373)$ & $16.0-27.0$ & 0.421 & N/A \\
\hline PEFR (\% pred) & $61(364)$ & $25.5-98.2$ & $<0.0001$ & $<0.001$ \\
\hline FVC (\% pred) & $62(373)$ & $31.4-99.1$ & $<0.0001$ & $<0.001$ \\
\hline $\mathrm{FEV}_{1}(\%$ pred $)$ & $43(373)$ & $19.3-86.0$ & $<0.0001$ & $<0.001$ \\
\hline Height (m) & $1.63(373)$ & $1.51-1.78$ & $<0.0003$ & $<0.001$ \\
\hline Weight (\% pred) & $82.0(351)$ & $71.1-100$ & $<0.0001$ & $<0.001$ \\
\hline Alkaline phosphatase (IU/1) & $225(365)$ & $130-571$ & 0.897 & $<0.05$ \\
\hline Albumin $(g / l)$ & $38(354)$ & $32-46$ & 0.0007 & $<0.001$ \\
\hline Bilirubin $(\mu \mathrm{mol} / \mathrm{l})$ & $7(359)$ & $3-16$ & 0.968 & $0.1<\mathrm{p}<0.2$ \\
\hline WBC $\left(\times 10^{9} / 1\right)$ & $10.8(373)$ & $6.9-17.0$ & 0.189 & $<0.001$ \\
\hline Haemoglobin $(\mathrm{g} / \mathrm{dl})$ & $13.5(364)$ & $11.8-15.4$ & 0.0006 & $<0.001$ \\
\hline Follow up (years) & $3.5(373)$ & $1.0-7.0$ & N/A & N/A \\
\hline Sex & \multicolumn{2}{|c|}{ Male $=169$, female $=204$} & 0.556 & N/A \\
\hline Splenomegaly & \multicolumn{2}{|c|}{$\begin{array}{l}\text { No splenomegaly }=349, \\
\text { splenomegaly }=24\end{array}$} & $<0.0001$ & $<0.001$ \\
\hline Hepatomegaly & \multicolumn{2}{|c|}{$\begin{array}{l}\text { No hepatomegaly }=319, \\
\text { hepatomegaly }=54\end{array}$} & 0.010 & $<0.001$ \\
\hline Malabsorption & \multicolumn{2}{|c|}{$\begin{array}{l}\text { No malabsorption }=148 \\
\text { malabsorption }=218\end{array}$} & 0.095 & * \\
\hline Diabetes & \multicolumn{2}{|c|}{ No diabetes $=326$, diabetes $=47$} & 0.005 & * \\
\hline Ascites & \multicolumn{2}{|c|}{ No ascites $=365$, ascites $=8$} & 0.469 & * \\
\hline Varices & \multicolumn{2}{|c|}{ No varices $=367$, varices $=4$} & 0.027 & * \\
\hline Pancreatic replacement & \multicolumn{2}{|c|}{$\begin{array}{l}\text { No replacement }=40 \\
\text { replacement }=331\end{array}$} & 0.022 & $*$ \\
\hline
\end{tabular}

$\mathrm{PEFR}=$ peak expiratory flow rate; $\mathrm{FVC}=$ forced vital capacity; $\mathrm{FEV}_{1}=$ forced expiratory volume in one second.

* These variables were recorded only at entry to the study.

zyme supplements; malabsorption defined as frequent, loose, pale or offensive stools that were difficult to flush away) and subsequent annual outpatient assessments. Routine haematology, serum biochemistry, and measurements of pulmonary function, nutritional and hepatic status were performed at these visits during periods of stability. Patients in whom data collection was incomplete were not included in the analysis. These routine data were collected prospectively on a computerised data base. Pulmonary function and weight were expressed as a percentage of the expected value. ${ }^{910}$

The year of entry to the study, considered to be the date of first full assessment at the Brompton Hospital, was included in all analyses to allow for the possible effect of changes in referral patterns and the development of improved treatment regimes. In addition, as the diagnosis of cystic fibrosis had been made some time before the initial assessment for most of the study population, the time from diagnosis to entry was calculated and entered into the analysis.

Sixteen patients were lost to follow up but were included in the analysis until the date they were last known to be alive. Three had returned to their homes abroad, 11 were transferred to other hospitals, and no information was available for the other two. Seven patients underwent transplantation during follow up and were therefore included until the date of transplantation. At this point they were excluded from further analysis and, for the purpose of the study, were regarded as having died during the period of follow up.

\section{Cohort B}

A second cohort of patients, recruited between October 1988 and September 1993, was used for validation purposes (cohort B). This data set included 100 patients (50 male) with an age range of $13-45$ years $(10-90 \%$ with age range 16-33 years). All were followed up for at least one year or died soon after referral.

DATA ANALYSIS

Variables for initial statistical screening were carefully selected to incorporate what the authors believe to be the most clinically significant factors reflecting the health of patients with cystic fibrosis whilst also attempting to incorporate factors reflecting time of recruitment to the study and length of follow up.

A total of 20 static and continuous variables were screened by log rank analysis for correlation with survival. Median values were used as end points for the continuous variables (table 1). Univariate Cox regression analysis, using log transformation if the variables had a skewed distribution, was performed separately on 12 time dependent variables as they changed over time (table 1). Variables that were significantly $(p<0.05)$ associated with survival when analysed by either test were then entered in a stepwise manner into both forward and backward stepping, time dependent, multivariate Cox regression analysis to select the subset of variables which best predicted survival. ${ }^{11}$

Multivariate Cox regression analysis requires that all patients be represented by a complete data set at the time of entry to the study so only 373 patients were included in the final analysis. The significant variables were combined into a predictive index (PI) and used to produce estimates of survival.

Multivariate Cox regression analysis produces a model of two parts. The first part is related to the current medical status and is therefore a function of PI, and the second is a multiplying hazard function (the risk of dying at any particular point in time) which is constant for all patients at that time point. ${ }^{11}$ If, as we later show, this underlying hazard function is constant over time, such that the risk of dying at or before a given time point increases linearly over time, then the probability of survival at any time point can be directly estimated from the PI.

\section{VALIDATION OF THE MODEL}

Internally (within cohort $A$ )

The model was validated for prediction of one year survival using split sample testing. ${ }^{11}$ The data base of 373 patients was randomly divided into two parts. The model was regenerated using three quarters of the data base and applied to the remaining one quarter. A predictive score was generated, at all time points, for each of the remaining patients using the model and, in combination with the underlying hazard function, used to calculate the probability of a particular patient dying within one year.

The observed and expected numbers of deaths were compared using the $\chi^{2}$ test.

\section{Externally (using cohort B)}

The predictive index (PI) was generated for each patient and the probability of dying within 
Table 2 Details of variables significant by multivariate Cox regression analysis and included in the final model

\begin{tabular}{llllll}
\hline Variable & Coefficient & SE & Coefficient $/ S E$ & p value & Relative risk $^{*}$ \\
\hline Height $(\mathrm{m})$ & -3.41 & 0.828 & -4.12 & $<0.0001$ & 0.033 \\
Hepatomegaly $(0,1)$ & 0.99 & 0.154 & 6.48 & $<0.0001$ & 2.69 \\
FVC (\% pred) & -0.038 & 0.009 & -3.27 & $<0.0001$ & 0.963 \\
FEV $_{1}(\%$ pred) & -0.059 & 0.013 & -4.46 & $<0.0001$ & 0.943 \\
WBC $\left(\times 10^{9} / 1\right)$ & 0.090 & 0.014 & 6.40 & $<0.0001$ & 1.095 \\
\hline * Relative risk = proportionate increase in risk of death per unit increase in the variable at any \\
point in time. \\
FVC=forced vital capacity; FEV $_{1}$ = forced expiratory volume in one second; WBC = white blood \\
cells.
\end{tabular}

one year was calculated. ${ }^{11}$ The patients were divided into five groups, the probabilities of death were calculated for each group to give the expected number of deaths for that group, and a comparison with the actual number of deaths was made using the $\chi^{2}$ test.

\section{Results}

The patient characteristics are shown in table 1. Three hundred and seventy three patients (169 male) of median age 20 years (range 11-63) were included in the final analysis, of which 188 (50.4\%) died.

The factors significant by either log rank analysis or univariate time dependent Cox regression analysis are shown in table 1. Age, sex, year of entry into the study, and time from diagnosis to entry into the study were not significant predictors of survival after the final analysis.

Time dependent multivariate Cox regression analysis revealed percentage predicted $\mathrm{FEV}_{1}$, percentage predicted FVC, height $(\mathrm{m})$, white blood cell count (WBC, $\times 10^{9} / 1$ ), hepatomegaly (palpable liver, confirmed by increased liver span), serum concentrations of albumin ( $\mathrm{g} / \mathrm{l}$ ) and alkaline phosphatase (ALP, IU/l) as factors significantly associated with survival. Serum concentrations of albumin and ALP were excluded from the final model, the former because its coefficient within the predictive model was only 0.0001 and the latter because, for individual patients, there was concern that bone related ALP might introduce a considerable inaccuracy.

The remaining significant variables (table 2) were combined to produce the final model: $\mathrm{PI}=(0.99 \times$ hepatomegaly $)-(3.41 \times$ height $)-$ $(0.038 \times \% \mathrm{FVC})-\left(0.0590 \times \% \mathrm{FEV}_{1}\right)+(0.090$ $\times$ WBC) where the presence of hepatomegaly $=1$; absence $=0$.

APPLICATION OF THE MODEL

The underlying hazard for this cohort of patients was constant over time $(r=0.996)$,

Table 3 Details of the external validation (cohort B) with patients subdivided according to probability of surviving one year, confirming the reproducibility of one year survival prediction

\begin{tabular}{llllll}
\hline \multicolumn{7}{c}{} & \multicolumn{5}{l}{ Probability of survival in one year } \\
\cline { 2 - 6 } & $>0.96$ & $\leq 0.96->0.73$ & $\leq 0.73->0.61$ & $\leq 0.61->0.27$ & $\leq 0.27$ \\
\hline Observed & 0 & 4 & 9 & 11 & 15 \\
Expected & 0.20 & 2.12 & 5.5 & 9.4 & 13.4 \\
$\chi^{2}$ & 0.20 & 1.66 & 2.22 & 0.27 & 0.19 \\
\hline
\end{tabular}

Total $\chi^{2}=4.54 ; 0.5>\mathrm{p}>0.4$ (NS).

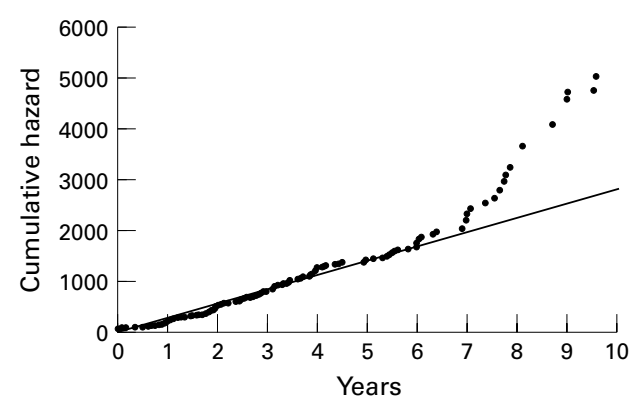

Figure 1 Graph of cumulative underlying hazard plotted against time.

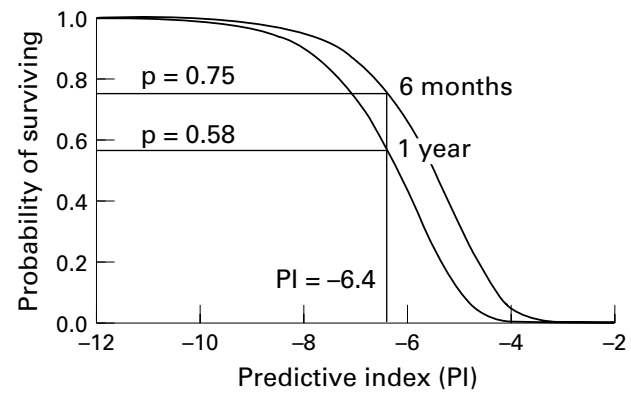

Figure 2 Graph relating predictive index to survival probability.

deviating only as the numbers of patients became small at seven years (fig 1 ). Thus, graphs relating the predictive index to the probability of survival over set periods of time can be generated (fig 2) and allow an estimate of the probability of survival to be made for specific periods of time. For example, for a patient of height $1.54 \mathrm{~m}$ who presents with hepatomegaly $=1$ (present), $\mathrm{FVC}=50 \%$ predicted, $\mathrm{FEV}_{1}=35 \%$ predicted, and $\mathrm{WBC}=20 \times 10^{9} / 1$ the predictive index is obtained by multiplying each variable by its coefficient:

$\mathrm{PI}=(-3.410 \times 1.54)+(0.990 \times 1)-(0.038 \times$ $50)-(0.059 \times 35)+(0.090 \times 20)=-6.4$

From fig 2 it can be seen that this patient has a $75 \%$ estimated chance of surviving six months, but only a $56 \%$ chance of surviving one year.

\section{RESULTS OF THE VALIDATION}

Internal (cohort $A$ )

The validation was performed twice. The data base was randomly split so that the first validation of the model used the "first" three quarters of the data, and the second used the "last" three quarters of the data base. In the first case the observed number of deaths was 65 and the expected number $60\left(\chi^{2}=0.41\right.$; $\mathrm{p}>0.4$ (NS)), and in the second there were 33 observed and 33.65 expected deaths $\left(\chi^{2}=\right.$ $0.012 ; \mathrm{p}>0.8$ (NS)).

\section{External (cohort B)}

The number of expected deaths as predicted by the model was calculated for this cohort and compared with the number of observed deaths. There was no statistically significant difference 
between the observed and expected deaths (table 3), which thus confirms the ability of the prognostic model to accurately predict one year survival.

\section{Discussion}

This study has enabled the construction of a model to predict short and medium term survival in patients with cystic fibrosis which has been validated within the study population (cohort A) and in a cohort recruited after October 1988 (cohort B). We believe this is the first report of a time dependent predictive model in this disease.

Its application to other cystic fibrosis populations remains to be assessed, but its confirmation by external validation, albeit in a cohort of patients referred to the same centre (but one which probably reflects the changing referral patterns consequent upon the more widespread availability of specialised cystic fibrosis centres in the UK), suggests wide applicability. This presumption is supported by reported similarities in median survival for patients with cystic fibrosis in the $\mathrm{UK}^{12}$ USA, ${ }^{13}$ Canada, ${ }^{13}$ and Denmark. ${ }^{14}$

The results of the external validation indicate the accuracy of the model in predicting the prognosis of patients with cystic fibrosis who are particularly unwell. This group is the one most likely to be considered for transplantation, suggesting that this model will allow accurate identification of patients in need of transplantation (table 3).

The characteristics of the cohort within this study were determined by hospital referral patterns and resulted in the analysis being of a predominantly adult population. This limits its applicability to the adult cystic fibrosis population but does not, however, diminish its value.

While there have been marked improvements in the management of patients with cystic fibrosis over the considerable time period of recruitment to this study, and also changes in the pattern of patient referral to the Brompton Hospital resulting recently in a more ill patient population (predominantly those with complications that have proved difficult to manage or those in need of transplant assessment), the failure of the year of entry into the study to reach statistical significance in the multivariate analysis suggests that any influence of these changes in patient population and treatment regimes on survival is accounted for by the variables included in the model. These changes do not therefore reduce the value of the prognostic index. Furthermore, the prognosis of patients recruited more recently, who are likely to reflect these changes in management and referral practice, appears to be well modelled by the predictive index as demonstrated by the results of the external validation.

Comparison of the results of this analysis with previous studies is hampered by the fact that most previous reports of prognosis in cystic fibrosis have assessed variables that affect the long term outcome and are not directly comparable with this analysis. In addition, some measures which have been shown to be cor- related with survival, such as colonisation with mucoid Pseudomonas aeruginosa, ${ }^{15}$ aerobic fitness, ${ }^{16}$ and functional status, ${ }^{17}$ were not evaluated. This was because the intention was to use variables that were universally available and easily measured.

The failure of both the age and sex of the patients to reach statistical significance within the model is at variance with some, ${ }^{281819}$ but not all, ${ }^{2021}$ previous reports. It has been suggested that the influence of both these factors on survival is related to the nutritional status of the patient. ${ }^{13}$ The inclusion of patient height, which may reflect nutritional status (see below), in this model may have resulted in the exclusion of age and sex from the prognostic index. However, this interrelationship between age, sex, and nutrition has not been universally reported with the most recent predictive model reporting an increased risk of death in young females with cystic fibrosis even when allowance is made for weight differences. ${ }^{8}$

While pulmonary function has not always been found to correlate with survival, ${ }^{20}$ other reports have documented the importance of deteriorating $\mathrm{FEV}_{1}$ and of carbon dioxide retention. ${ }^{8223}$ Within this model both percentage predicted $\mathrm{FEV}_{1}$ and FVC were negatively correlated with survival. The inclusion of two parameters which reflect pulmonary disease suggests that each provides independent prognostic information, although the mechanism for their independent effect upon survival is unclear.

Other parameters reflecting pulmonary function, including oxygen saturation and arterial blood gas measurements, were not included in the analysis as these were not routinely performed before the mid 1970s. However, the importance of the arterial blood gas tensions in prognostic evaluation is well recognised ${ }^{8}$ and it is hoped to be able to include them in future analyses.

Nutritional status has also been documented as an important predictor of prognosis ${ }^{1320}$ although there are no studies to show that nutritional intervention leads to improvement in long term survival. ${ }^{24}$ In this analysis taller patients survive longer. The precise relationship of height to survival remains unclear, but failure of statural growth probably reflects a degree of malnutrition $^{25}$ and may also be a long term marker of disease severity.

The prognostic model also includes two factors that have not previously been reported as predictors of outcome. The negative correlation of a high WBC (measured on blood samples obtained during periods of stability) with survival may reflect chronic ongoing sepsis, presumably of pulmonary origin, and the observation that WBC and pulmonary function are independent prediction variables suggests that mechanisms other than pulmonary disease alone may be involved. It may be speculated that an increase in inflammatory mediators secondary to sepsis, such as tumour necrosis factor $\alpha$, may have a systemic adverse effect. ${ }^{26}$

Established chronic liver disease, as manifest by hepatomegaly, also proved to be an important negative correlate with survival. Con- 
cerns that hepatomegaly might represent a poor predictor of chronic liver disease with interobserver variation may have credence for individual patients ${ }^{27}$ but has been identified as a good marker for liver disease in cystic fibrosis $^{28}$ and has proved of value in this statistical model (relative risk 2.69). Further support comes from two other cholestatic liver diseases - primary sclerosing cholangitis ${ }^{29}$ and primary biliary cirrhosis $^{30}$ - for which hepatomegaly has been shown to correlate significantly with reduced survival.

This previously largely unsuspected influence of liver disease upon survival highlights two areas which may become increasingly important in the longer term management of patients with cystic fibrosis - firstly, the accurate documentation of those patients with and without significant hepatic involvement and, secondly, the identification of a therapeutic agent effective for the treatment of patients with liver disease.

In the current cohort of patients very few deaths were directly attributable to overt complications of chronic liver disease $(2.2 \%)$. This observation is in keeping with a recent retrospective analysis of a cohort of 1100 patients with cystic fibrosis in which only $7.8 \%$ of deaths in those patients with liver disease were directly related to the liver disease ${ }^{31}$ and suggests a covert influence of liver disease upon survival. This covert effect remains to be elucidated but may be related to the nutritional, ${ }^{3233}$ immunological, ${ }^{3435}$ and haemodynamic ${ }^{3637}$ consequences of chronic liver disease. The identification of the most important determining factors offers potential for therapeutic intervention.

The importance of accurate prediction of survival to facilitate timing of heart-lung transplantation is well recognised. ${ }^{78}$ This model represents a simple method, which should be applicable to other adult cystic fibrosis populations, for improving timing to transplantation. It should be a valuable addition to the available criteria for judging the short and medium term management of patients with cystic fibrosis.

We are grateful to Professor S Evans of The Royal London Hospital Medical College for statistical help and advice.

1 Wood RE, Boat TF, Doershuk CF. Cystic fibrosis. Am Rev Respir Dis 1976;113:833-78.

2 British Paediatric Association Working Party on Cystic Fibrosis. Cystic fibrosis in the United Kingdom 1977-1985, an improving picture. BMF 1988;297:1599-602.

3 MacLusky I, Levison H. Cystic fibrosis. In: Chernick V, ed. Disorders of the respiratory tract in children. Philadelphia: WB Saunders, 1990:692-729.

4 Madden BP, Hodson ME, Tsang V, Radley-Smith R, Khaghani A, Yacoub MY. Intermediate-term results of heartlung transplantation for cystic fibrosis. Lancet 1992;i: 1583-7.

5 Scott J, Higenbottam T, Hutter J, Hodson M, Stewart S, Penketh A, et al. Heart-lung transplantation for cystic fibrosis. Lancet 1988;ii:192-4.

6 Whitehead B, Helms P, Goodwin M, Martin I, Scott JP, Smyth RL, et al. Heart-lung transplantation for cystic fibrosis. 2. Outcome. Arch Dis Child 1991;66:1022-6.

7 Whitehead B, Helms P, Goodwin M, Martin I, Lask B, Serrano E, et al. Heart-lung transplantation for cystic ferrano E, et al. Heart-lung transplantation for cystic
fibrosis. 1. Assessment. Arch Dis Child 1991;66:1018-21.
8 Kerem E, Reisman J, Corey M, Canny GJ, Levison $\mathrm{H}$. Prediction of mortality in patients with cystic fibrosis. $N$ Engl f Med 1992;326:1187-91.

9 Bates DV, Macklem PT, Christie RV. Respiratory function in disease. Philadelphia: WB Saunders, 1971:93-4.

10 Society of Actuaries (Chicago). Build and blood pressure study. New York: Peter F Mallon Inc, 1959:16-23.

11 Christensen E, Schlichting P, Andersen PK, Fauerholdt L, Schou G, Pedersen BV, et al. Updating prognosis and therapeutic effect evaluation in cirrhosis with Cox's multiple regression model for time-dependent variables. Scand f Gastroenterol 1986;21:163-74.

12 British Paediatric Association Working Party on Cystic Fibrosis. Cystic fibrosis in the United Kingdom 1968-88: incidence, population and survival. $\mathcal{f}$ Paediatr Peri Epiincidence, population

13 Corey M, McLaughlin FJ, Williams M, Levison H. A comparison of survival, growth, and pulmonary function in patients with cystic fibrosis in Boston and Toronto. 7 Clin patients with cystic fibrosis

14 Niellsen OH, Schiotz PO. Evaluation of centralised treatment 1945-1981. Acta Paediatr Scand 1982;Suppl 301: 107-19.

15 Henry RL, Mellis CM, Petrovic L. Mucoid Pseudomona aeruginosa is a marker of poor survival in cystic fibrosis. Pediatr Pulmonol 1992;12:158-61.

16 Nixon PA, Orenstein DM, Kelsey SF, Doershuk CF. The prognostic value of exercise testing in patients with cystic fibrosis. $N$ Engl f Med 1992;327:1785-8.

17 Shepherd SL, Hovell MF, Slymen DJ, Harwood IR, Hofstetter CR, Granger LE, et al. Functional status as an overall measure of health in adults with cystic fibrosis: further validation of a generic health measure. F Clin Epidemiol 1992;45:117-25.

18 Elborn JS, Shale DJ, Britton JR. Cystic fibrosis: current survival and population estimates to the year 2000. Thorax $1991 ; 46: 881-5$

19 Britton JR. Effects of social class, sex, and region of residence on age of death from cystic fibrosis. BMf 1989;298:483-7.

20 Huang NN, Schidlow DV, Szatrowski TH, Palmer J, LarayaCuasay LR, Yeung W, et al. Clinical features, survival rate and prognostic factors in young adults with cystic fibrosis. Am $\mathcal{F}$ Med 1987;82:871-9.

21 Hudson I, Phelan PD. Are sex, age at diagnosis, or mode of presentation prognostic factors in young adults with of presentation prognostic factors in young adut
cystic fibrosis. Pediatr Pulmonol 1987;3:288-97.

22 Wagener JS, Taussig LM, Burrows B, Hernried L, Boat T Comparison of lung function and survival patterns between cystic fibrosis and emphysema or chronic bronchitis patients. In: Strurgess JM, ed. Perspectives in cystic fibrosis: proceedings of the 8th International Cystic Fibrosis Congress, Mississauga, Ontario. Mississauga: Imperial Press, 1980 236-45.

23 Sharples L, Hathaway T, Dennis C, Caine N, Higenbottam T, Wallwork J. Prognosis of patients with cystic fibrosis awaiting heart and lung transplantation. $f$ Heart Lung Transplant 1993;12:669-74.

24 Levy LD, Durie PR, Pencharz PB, Corey ML. Effects of long-term nutritional rehabilitation on body composition and clinical status in malnourished children and adolescents with cystic fibrosis. F Pediatr 1985;107:225-30.

25 Editorial. Survival in cystic fibrosis - how important is nutrition? Lancet 1988;ii:1060-1.

26 Elborn JS, Cordon SM, Western PJ, MacDonald IA, Shale DJ. Tumour necrosis factor- $\alpha$, resting energy expenditure and cachexia in cystic fibrosis. Clin Sci 1993;85:563-8.

27 Tanner MS. Liver and biliary problems in cystic fibrosis. $\mathcal{F}$ $R$ Soc Med 1992;85(Suppl 19):20-4.

28 Gaskin KJ, Waters DLM, Howman-Giles R, De Silva M, Earl JW, Martin HCO, et al. Liver disease and commonEarl JW, Martin HCO, et al. Liver disease and common-
bile-duct stenosis in cystic fibrosis. N Engl f Med 1988; 318:340-6.

29 Farrant JM, Hayllar KM, Wilkinson ML, Karani J, Portmann BC, Westaby D, et al. Natural history and prognostic variables in primary sclerosing cholangitis. Gastroenterology variables in primary

30 Roll J, Boyer JL, Barry D, Klatskin G. The prognostic importance of clinical and histological features in asymptomatic and symptomatic primary biliary cirrhosis. $N$ Eng f Med 1983;308:1-7.

31 Scott-Jupp R, Lama M, Tanner MS. Prevalence of liver disease in cystic fibrosis. Arch Dis Child 1991;66:698-701. 32 Sproul A, Huang NN. Growth patterns in children with cystic fibrosis. F Pediatr 1964;65:664-75.

33 Sokol RJ, Stall C. Anthropometric evaluation of children with chronic liver disease. Am F Clin Nutr 1990;52:203-8. 34 Feizi T. Immunoglobulins in chronic liver disease. Gut 1968 9:193-8.

35 Webb LJ, Ross M, Markham RL, Webster ADW, Thomas $\mathrm{HC}$, Sherlock S. Immune function in patients with extrahepatic portal venous obstruction and the effect of splenectomy. Gastroenterology 1980;79:99-103.

36 Bosch J, Arroyo V, Rodes J. Hepatic and systemic haemodynamics and the renin-angiotensin-aldosterone system in cirrhosis. In: Epstein M, ed. The kidney in liver disease. New York: Elsevier Biomedical, 1983:423-40.

37 Rodriguez-Roisin R, Agusti AGN, Roca J. Pulmonary function and liver disease. Curr Opin Gastroenterol 1988;4: 609-14. 